\title{
Corrigendum: Regulation of histone modification and chromatin structure by the p53-PADI4 pathway
}

Chizu Tanikawa, Martha Espinosa, Akari Suzuki, Ken Masuda, Kazuhiko Yamamoto, Eiju Tsuchiya, Koji Ueda, Yataro Daigo, Yusuke Nakamura \& Koichi Matsuda

Nature Communications 3:676 doi: 10.1038/ncomms1676 (2012); Published 14 Feb 2012; Updated 16 Oct 2013

When preparing Fig. 6 for this Article, the labels 'Padi $4^{+/+}$' and 'Padi4 ${ }^{-/-}$' at the foot of the histograms in panels b, $\mathrm{c}$ and $\mathrm{d}$ were accidentally placed under the wrong bars. The correct version of Fig. 6 appears below.

a

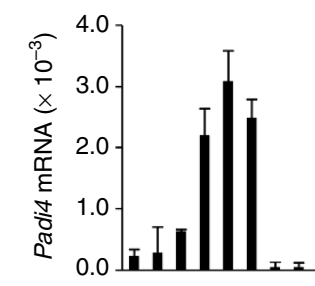

$\gamma$-ray (3 Gy) $\frac{-}{\text { Padi4 }^{+/+}} \frac{-}{-} \overline{+}$

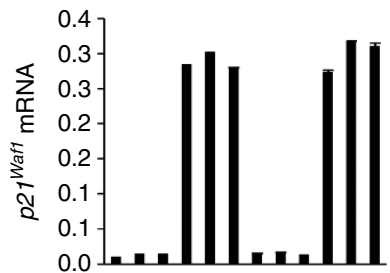

$\gamma$-ray (3 Gy)

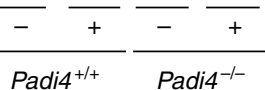

\section{b}

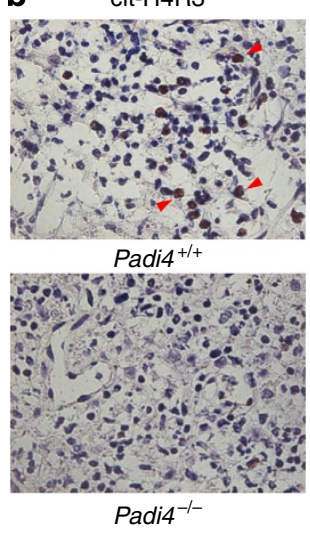

d Cleaved caspase-3
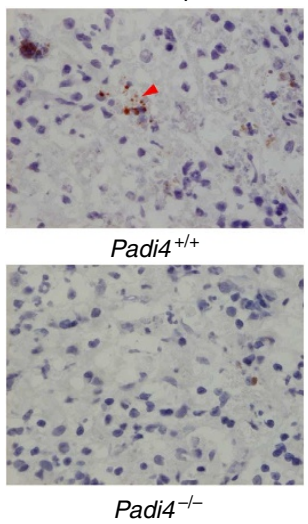
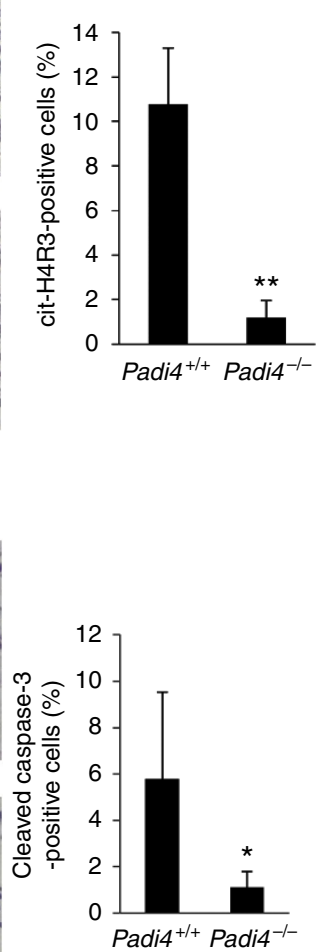

C

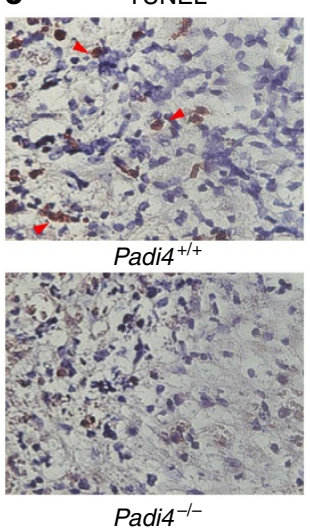

$\mathbf{e}$

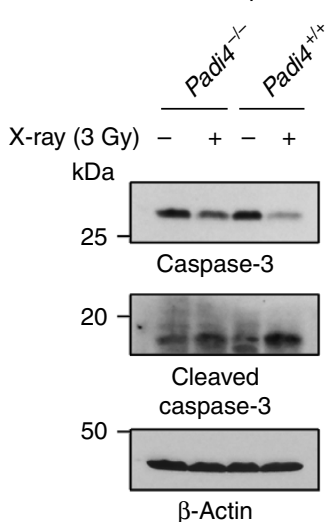

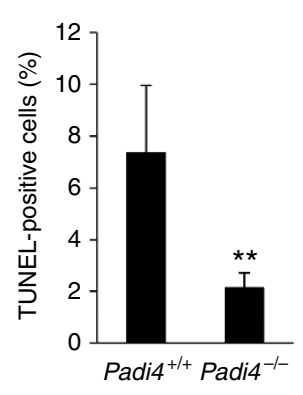

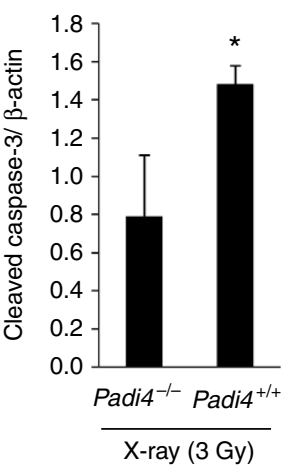

